\title{
Reflex arc of the first component of the human blink reflex: a single motoneurone study
}

\author{
MELITA A. TRONTELJ AND JOŽE V. TRONTELJ \\ From the Institute of Clinical Neurophysiology, The University Hospitals, Ljubljana, Yugoslavia
}

S U M MARY Latency variation of consecutive responses of single orbicularis oculi motoneurones in the first component of the electrically elicited blink reflex was 2.6 times larger than that of the $\mathrm{H}$ reflex of the soleus muscle fibres. Some motoneurones showed bimodal latency distribution or double responses or both at an interval of about 4-5 ms. Typical first component responses were sometimes obtained by contralateral stimulation. Central conduction time in the brainstem, estimated for 15 motoneurones, was between 2.4 and $6.6 \mathrm{~ms}$. It is concluded that the first component of the blink reflex is conducted through an oligosynaptic arc including one or more interneurones.

There are different views on the reflex arc of the first component of the blink reflex in man. Early descriptions have interpreted the origin of the blink reflex as a cutaneous (Overend, 1896), periosteal (Bechterew, 1901; Foerster, 1936), cutaneoperiosteal (Guillain, 1920), perichondral (Simchowicz, 1922), osseous (Lewandowsky, 1910), and finally as a stretch reflex (Weingrow, 1933; Wartenberg, 1945).

Electromyographic studies have shown that both mechanically and electrically evoked blink reflexes consist of two components (Kugelberg, 1952). There has been no doubt that the second component is a polysynaptic reflex but the nature of the first component is still discussed. Kugelberg (1952) believed that it was a typical monosynaptic stretch reflex. He based his conclusion on calculation of the central delay and on the fact that stretch appeared to be the adequate stimulus. This view has been accepted by a number of subsequent authors (Rushworth, 1962; Gandiglio and Fra, 1967; Bender, 1968; Ferrari and Messina, 1968; Brown and Rushworth, 1973). Struppler and Dobbelstein (1963) agreed that the first component might well be a proprioceptive reflex, but they thought that the reflex arc was at least disynaptic as indicated by the anatomical studies of trigeminofacial connections reported by Ramon Y. Cajal (1909).

Address for reprint requests: Dr J. Trontelj, Institute of Clinical Neurophysiology, The University Hospitals, Zaloska 7, 61105 Ljubljana, Yugoslavia.

Accepted 25 January 1978
Shahani $(1968,1970)$ and Shahani and Young $(1968,1972)$ objected to the hypothesis of the proprioceptive nature of the first component. They postulated that this reflex is elicited by stimulating cutaneous afferent nerve fibres. Furthermore, Shahani claimed that the first component of the blink reflex is perfectly analogous to the first EMG component of the flexion withdrawal reflex (Shahani, 1969, 1970).

Experimental work in the cat has shown that the first component of the blink reflex in this animal is mediated through at least one interneurone (Lindquist and Mårtensson, 1970; Iwata et al., 1972). The former authors have succeeded in eliciting the reflex by tapping the lifted skin flap overlying the orbicularis oculi, but not by tapping the muscle directly. Similar results were obtained by Shahani and Young (1973) in the monkey.

The present work was started in the hope that observation of the blink reflex on single facial motoneurones by single fibre EMG might resolve the nature of its first component. A preliminary report has already been published (Trontelj and Trontelj, 1973a).

\section{Method}

The blink reflex was elicited electrically and mechanically. The electrical stimulus was a square pulse of $30-200 \mathrm{~V}$ and $50 \mu \mathrm{s}$ duration delivered through a pair of silver cup electrodes attached to the skin over the supraorbital foramen. Three intensities were used for each motoneurone studied: 
threshold, at which about $50 \%$ of the stimuli were effective in producing a response; intermediate, which was 50 or $100 \%$ higher; and maximum which was 100 or $200 \%$ higher than the threshold intensity (increments by $50 \%$ were made in those cases where the threshold intensity was already rather high and increments by $100 \%$ would be too painful).

Mechanical stimuli were brief taps delivered by an electrodynamic hammer (Trontelj et al., 1968). They were applied perpendicularly to the supraorbital region. Again three stimulus intensities were used, determined in the same way as with the electrical stimulus. Both electrical and mechanical stimuli were delivered with a rate of one per 3 seconds to minimise synaptic exhaustion.

Direct responses were elicited by surface stimulation of the facial nerve trunk or its peripheral branches with a pointed cathode pressed to the skin, the anode being a silver plate attached to the neck. The rate of stimulation was 1-10 per second, and stimulus intensity was well above the threshold.

The responses were recorded in two ways: first, with a pair of silver cup electrodes attached below the lower lid about $20 \mathrm{~mm}$ apart, the dc resistance across them being reduced below $10 \mathrm{k}$ ohms, and with a special needle electrode (Ekstedt et al., 1969). With this electrode it was possible to isolate action potentials of single orbicularis oculi muscle fibres and thus to study successive responses of single facial motoneurones. These potentials were recognised as being generated by a single fibre according to the following criteria: that they were smooth biphasic potentials, remaining constant in shape, amplitude, and duration on consecutive discharges at a time resolution of at least $10 \mu \mathrm{s}$ (Ekstedt and Stålberg, 1969). Another criterion used for reliable identification of the motoneurone studied was that potentials of similar parameters but generated by neighbouring muscle fibres of other motor units did not appear in the tracing (Trontelj, 1973; Trontelj and Trontelj, 1973b). Identification was even easier when two or more muscle fibres of the same motor unit were recorded by the electrode. In this case the complex action potential consisted of two or more timelocked spikes appearing according to the all-ornothing principle with a small jitter between the individual components. (The jitter is defined as variation of interpotential intervals on consecutive discharges, and is normally mostly due to changes in the delay time at the individual motor endplates (Ekstedt and Stålberg, 1973; Stålberg and Ekstedt, 1973).)
The consecutive responses of individual motoneurones (Fig. 1) showed variation of the latency which was measured automatically by means of a computer system with a resolution of 5 or $10 \mu \mathrm{s}$. The surface-detected responses were rectified and integrated. Series of 50 consecutive responses were analysed, two equal series for each stimulus strength. The following statistical parameters were computed: mean latency of the single motoneurone responses, standard deviation of the latency as a measure of latency variation, mean magnitude and standard deviation of surfacedetected responses, and cross-correlation between latency of single motoneurone responses and magnitude of surface-detected responses. Computation was performed mostly on-line and only in a few cases off-line from recordings on magnetic tape.

The experiments were performed in 10 young adults without history or signs of neurological disorders.

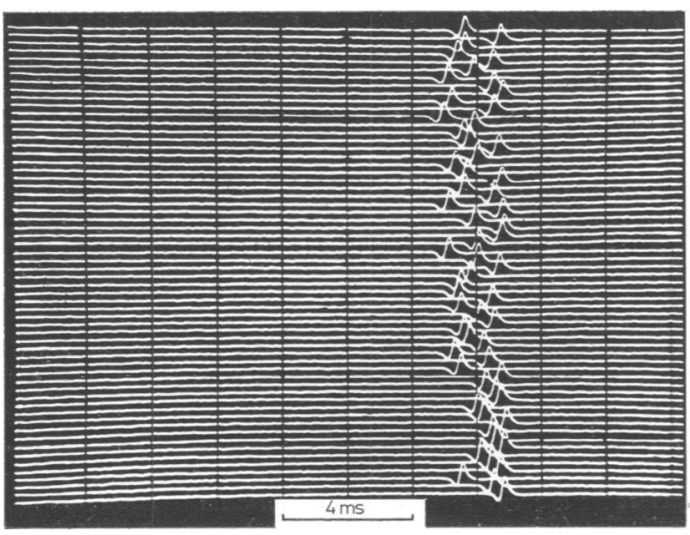

Fig. 1 Responses of a single orbicularis oculi muscle fibre in the first component of the blink reflex.

\section{Results}

Latency variation of individual motoneurone responses in the electrically and mechanically evoked first component of the blink reflex was measured in order to make a comparison with latency variation in the $\mathrm{H}$ reflex and tendon jerk of the soleus muscle. Latency variation of the direct responses of the same muscle fibres was measured to estimate the contribution of peripheral factors to the total latency variation of electrically evoked reflex responses. The remaining part was taken to be due to the variation of the synaptic delay. We also attempted to estimate the fraction of the latency representing the central delay in the brainstem. 
LATENCY VARIATION OF ELECTRICALLY EVOKED FIRST COMPONENT OF THE BLINK REFLEX

The complete measurement, including two series of 50 responses at each of the three stimulus intensities, was carried out on 21 motoneurones which were sampled from 10 subjects. The results are presented in Table 1 and Fig. 2, which also shows similarly obtained data for 25 soleus motoneurones in the $\mathrm{H}$ reflex. It can be noted that the mean latency shortens progressively as stimulus strength increases. The shortening is considerably larger than in the case of the $\mathrm{H}$ reflex (588 $\mu$ s as compared to $352 \mu \mathrm{s})$. The mean variation of the latency for all motoneurones and all the stimulus strengths was $1801 \mu \mathrm{s}$ (expressed as range) and $392 \mu \mathrm{s}$ (expressed as SD). Thus the latency variation of the first component of the electrically evoked blink was 2.4 times (range) or 2.6 times (SD) larger than that of the $H$ reflex.

\section{LATENCY VARIATION OF DIRECT RESPONSES}

Latency of consecutive direct responses to electrical stimulation of the facial motor axons or their branches varied much less than the latency of the reflex responses. Eleven motoneurones in which latency variation of electrically and mechanically

Table 1 Responses of 21 orbicularis oculi motoneurones in the first component of the electrically evoked blink reflex: means and standard deviations of two series of 50 responses of each neurone and each stimulus intensity. Cross-correlation coefficient is computed between the latency of the single neurone responses and the magnitude of the surface-detected EMG responses

\begin{tabular}{lllll}
\hline $\begin{array}{l}\text { Stimulus } \\
\text { intensity }\end{array}$ & $\begin{array}{l}\text { Mean } \\
\text { latency } \\
(\mu S)\end{array}$ & $\begin{array}{l}\text { SD of } \\
\text { latencies } \\
(\mu s)\end{array}$ & $\begin{array}{l}\text { Range of } \\
\text { latencies } \\
(\mu s)\end{array}$ & $\begin{array}{l}\text { Cross- } \\
\text { correlation } \\
\text { coefficient }\end{array}$ \\
\hline Threshold & $14389 \pm 2695$ & $420 \pm 103$ & $1863 \pm 507$ & $-0.59 \pm 0.21$ \\
\hline Intermediate & $14054 \pm 2772$ & $376 \pm 130$ & $1785 \pm 706$ & $-0.64 \pm 0.23$ \\
\hline Maximum & $13831 \pm 2680$ & $380 \pm 154$ & $1755 \pm 849$ & $-0.57 \pm 0.23$ \\
\hline
\end{tabular}

evoked reflex responses was determined (Table 2) could also be isolated and studied in the direct responses. The mean latency variation of the direct responses of these motoneurones was $14 \pm 8$ $\mu \mathrm{S}$ (SD), which is only $3.6 \%$ of the mean latency variation of electrically elicited reflex responses and $1.6 \%$ of the latency variation of mechanically elicited reflex responses. Another 27 motoneurones were studied in the same way; their mean latency variation was $16.5 \pm 8 \mu \mathrm{s}$.

LATENCY VARIATION OF MECHANICALLY EVOKED FIRST COMPONENT OF THE BLINK REFLEX

Eleven of the same 21 motoneurones were also studied in the mechanically evoked first component of the blink reflex (Table 2). The mean
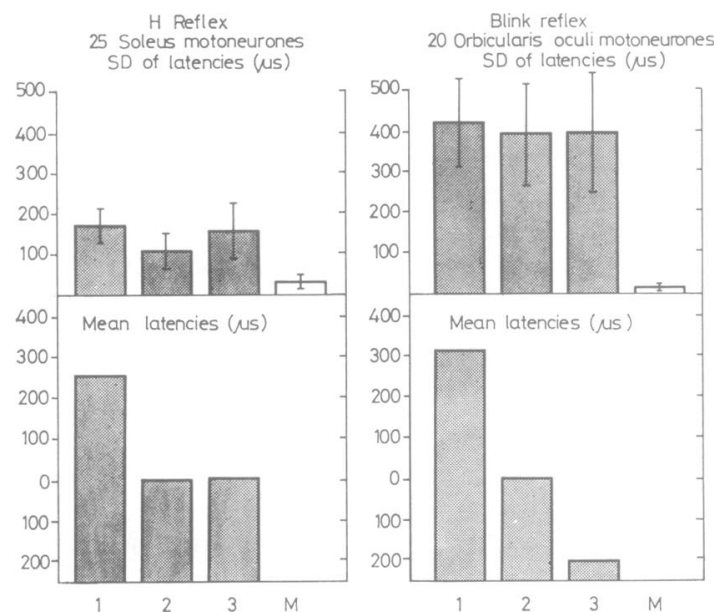

Fig. 2 Comparison between $H$ reflex and blink reflex at increasing stimulus strengths (1-3), and the direct $(M)$ responses of most of these motoneurones. Changes in mean latencies refer to mean latency at intermediate stimulus strength. Values were obtained from 100 consecutive responses of each of the 20 or 25 motoneurones at each stimulus strength. (Reproduced by permission of Brain Research.)

Table 2 Responses of 11 orbicularis oculi motoneurones in the first component of mechanically and electrically evoked blink reflex and responses to direct stimulation of the motor axons. Values are means and standard deviations of two series of 50 responses for each motoneurone and each stimulus strength

\begin{tabular}{|c|c|c|c|c|c|}
\hline Responses & Stimulus strength & $\begin{array}{l}\text { Mean latency } \\
(\mu s)\end{array}$ & $\begin{array}{l}S D \text { of latencies } \\
(\mu s)\end{array}$ & $\begin{array}{l}\text { Range of } \\
\text { latencies }(\mu s)\end{array}$ & $\begin{array}{l}\text { Cross-correlation } \\
\text { coefficient }\end{array}$ \\
\hline Mechanically evoked blink reflex & $\begin{array}{l}\text { Threshold } \\
\text { Intermediate } \\
\text { Maximum }\end{array}$ & $\begin{array}{l}19205 \pm 2928 \\
18496 \pm 2974 \\
17876 \pm 2886\end{array}$ & $\begin{array}{l}941 \pm 268 \\
856 \pm 308 \\
798 \pm 458\end{array}$ & $\begin{array}{l}4101 \pm 1364 \\
3796 \pm 1147 \\
3500 \pm 1149\end{array}$ & $\begin{array}{l}-0.54 \pm 0.15 \\
-0.60 \pm 0.14 \\
-0.55 \pm 0.14\end{array}$ \\
\hline Electrically evoked blink reflex & $\begin{array}{l}\text { Threshold } \\
\text { Intermediate } \\
\text { Maximum }\end{array}$ & $\begin{array}{l}14805 \pm 2739 \\
14408 \pm 2724 \\
14129 \pm 2743\end{array}$ & $\begin{array}{l}417 \pm 107 \\
335 \pm 126 \\
321 \pm 140\end{array}$ & $\begin{array}{l}1919 \pm 500 \\
1540 \pm 483 \\
1484 \pm 556\end{array}$ & $\begin{array}{l}-0.64 \pm 0.15 \\
-0.63 \pm 0.21 \\
-0.54 \pm 0.19\end{array}$ \\
\hline Direct & Suprathreshold & & $14 \pm 8$ & & \\
\hline
\end{tabular}


latency variation for all three stimulus intensities was $3799 \mu$ s (range) and $865 \mu \mathrm{S}$ (SD) as compared to $1648 \mu \mathrm{s}$ (range) and $358 \mu \mathrm{s}$ (SD) in the electrically evoked reflex of the same 11 motoneurones. On increasing the stimulus intensity the mean latency shortened more than in the case of electrical stimulation (1329 $\mu \mathrm{s}$ as compared to $676 \mu \mathrm{s}$, from threshold to maximum intensity).

The mechanical stimulus was considerably more effective if the hammer direction was not perpendicular but oblique to the skin of the forehead so that the taps resulted in a stretch rather than in vertical deformation of the skin and underlying tissues.

In all motoneurones activated either electrically or mechanically in the first component of the blink reflex there was a high negative crosscorrelation between the latency of consecutive responses and the size of simultaneous surfacedetected responses of the population of orbicularis oculi motoneurones (mean $-0.58, \mathrm{P}<0.001$ ).

ESTIMATION OF THE CENTRAL DELAY

The measurement of the central delay was expected to contribute to the resolution of the question whether the first component of the blink reflex is monosynaptic or polysynaptic. Two methods were used.

Method based on determination of conduction times After measuring the shortest possible latency of the electrically evoked reflex of a selected muscle fibre, the motor axon was stimulated directly at two points-over the zygomatic arch and over the stylomastoid foramen. Conduction velocity along the facial axon was calculated from the difference of the latencies of the two direct responses and the distance between the two stimulating cathodes. It was assumed that the conduction velocity in the central portion of the facial axon was the same as that calculated for the peripheral part. Conduction velocity along the central part of trigeminal nerve fibres was regarded as $70 \mathrm{~m} / \mathrm{s}$ (Kugelberg, 1952). Their length from the supraorbital foramen to the pontine nucleus of the trigeminal nerve was $102 \mathrm{~mm}$ as measured in two anatomical preparations, and the length of the central portion of the facial nerve fibres from the nucleus to the stylomastoid foramen was 105 $\mathrm{mm}$, measured in five preparations; $0.5 \mathrm{~ms}$ was taken for synaptic transmission to the facial motoneurone. By subtracting the afferent and efferent conduction times and the synaptic transmission from the total reflex latency we obtained an estimate of the central delay (Table 3), which ranged from 2.40 to $6.60 \mathrm{~ms}$, mean $4.19 \mathrm{~ms}$.

There was no correlation between the estimated central delay and the total reflex latency. However, there was significant correlation between the central delay and reflex latency from which the terminal conduction time had been subtracted (Fig. 3). This is because of great differences in terminal conduction times which tend to obscure the differences in central conduction time.

Table 3 Central delays of responses in the electrically evoked first component of the blink reflex in 15 facial motoneurones. $S Z$ is reflex latency less terminal conduction time between the zygomatic arch and the recording site, SO is total latency of the electrically evoked response. Central delay: (a) computed according to the method based on conduction times, and $(b)$ computed by the collision method

\begin{tabular}{|c|c|c|c|c|c|}
\hline \multirow{2}{*}{$\begin{array}{l}\text { Moto- } \\
\text { neurone } \\
\text { number }\end{array}$} & \multicolumn{2}{|c|}{ Central delay $(\mathrm{ms})$} & \multirow[b]{2}{*}{$S Z(m s)$} & \multirow[b]{2}{*}{$S O(m s)$} & \multirow{2}{*}{$\begin{array}{l}\text { Efferent } \\
\text { conduction } \\
\text { velocity } \\
(\mathrm{m} / \mathrm{s})\end{array}$} \\
\hline & (a) & (b) & & & \\
\hline 1 & 2.40 & & 7.50 & 10.30 & 62.5 \\
\hline 2 & 3.08 & & 8.00 & 10.56 & 55.0 \\
\hline 3 & 3.25 & & 8.12 & 12.72 & 59.0 \\
\hline 4 & 3.45 & 3.00 & 8.03 & 13.02 & 75.0 \\
\hline 5 & 3.62 & & 8.47 & 12.50 & 59.2 \\
\hline 6 & 3.91 & & 8.06 & 11.74 & 77.8 \\
\hline 7 & & 4.00 & & 14.76 & \\
\hline 8 & 4.05 & 4.00 & 8.61 & 11.97 & 70.3 \\
\hline 9 & 4.08 & & 8.20 & 13.67 & 81.0 \\
\hline 10 & 4.10 & & 9.40 & 16.00 & 50.0 \\
\hline 11 & 4.24 & 4.00 & 9.25 & 17.80 & 75.0 \\
\hline 12 & 4.47 & & 9.31 & 10.92 & 63.5 \\
\hline 13 & 4.67 & & 8.86 & 12.52 & 72.0 \\
\hline 14 & 4.77 & & 8.50 & 12.00 & 60.0 \\
\hline 15 & 6.60 & & 9.80 & 18.40 & 50.0 \\
\hline Mean & 4.05 & 3.75 & 8.58 & 13.26 & 65.0 \\
\hline SD & 0.98 & 0.50 & 0.66 & 2.47 & 10.19 \\
\hline
\end{tabular}

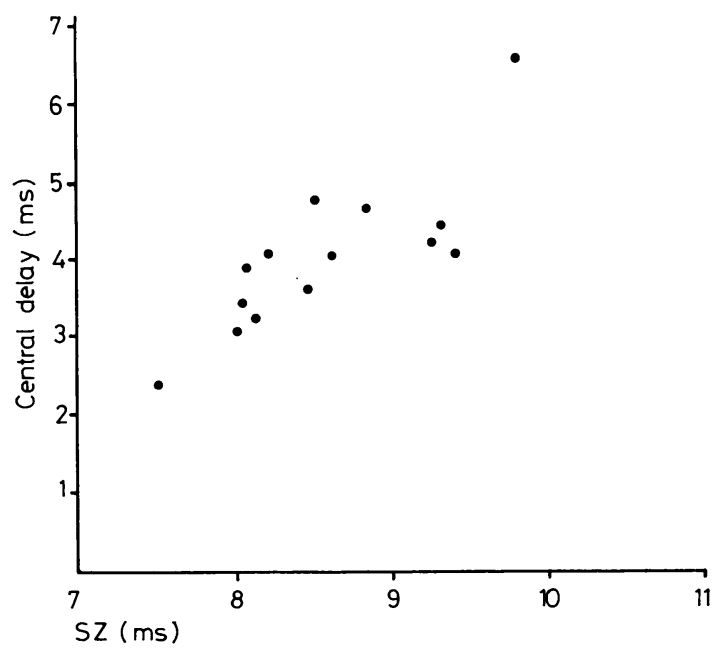

Fig. 3 Relationship between the central delay and the estimated conduction time between the supraorbital foramen and the zygomatic arch (SZ), that is, reflex latency minus terminal conduction time. 
Method based on collision of antidromic and reflex impulse We tried to determine the interval between triggering the reflex volley in the supraorbital nerve and the antidromic volley in the facial nerve at which collision occurs in the most proximal part of the facial motoneurone, resulting in extinction of the reflex response. Stimuli were applied at the stylomastoid foramen and at the supraorbital foramen, thus making the afferent and efferent pathway practically equal. If we may assume that there is no essential difference between the afferent and efferent conduction velocity, then the central delay is approximately equal to the critical interval between the two stimuli. However this method could be applied successfully only in a small number of neurones. In others the reflex responses were already almost totally depressed at much shorter intervals which we felt to be due to partial refractoriness of the antidromically activated motoneurones. Supposedly, this measurement was only possible in those cases where antidromic invasion of the motoneurone cell failed at least intermittently. Even the increasing refractoriness of the initial segment of the axon near the critical interval could reduce progressively the frequency of the responses. For this reason the interstimulus interval was changed in comparatively large steps of 0.25 to $0.50 \mathrm{~ms}$. Nevertheless the values agreed fairly well with those obtained by the method described previously (Table 3).

\section{RESPONSES WITH CHARACTERISTICS OF THE FIRST} COMPONENT OF THE BLINK REFLEX TO STIMULATION OF THE CONTRALATERAL SIDE OF THE FACE

In 10 motoneurones of the facial nerve of four subjects, typical first component responses were obtained to electrical and mechanical stimulation in the distribution not only of the ipsilateral but also of the contralateral supraorbital nerve. In four motoneurones the number of reflex responses to stimulation of both sides was sufficient to allow the usual statistical analysis.

For two motoneurones the mean latency of 200 consecutive responses was only insignificantly longer when stimulating on the contralateral side -0.04 and $0.09 \mathrm{~ms}$ respectively (Table 4). Mean latency variation (SD) was in one case larger and in the other case even smaller than on ipsilateral stimulation. According to the $t$ test, however, there was no significant difference between the distributions of data on ipsilateral and contralateral stimulation.

On mechanical stimulation it was possible, in practically every case, to evoke reflex responses in the first component by stimulating the contralateral side of the forehead. This was achieved by
Table 4 Responses of four motoneurones of the facial nerve in the first component of the blink reflex to stimulation of the contralateral side of the face. Electrical stimulation of the supraorbital nerve (neurones 1 and 2), perpendicular tapping of the supraorbital foramen (neurone 3), and tapping to the infraorbital region (neurone 4). Mean latencies and latency variation (SD) of 200 consecutive responses on ipsilateral and contralateral stimulation

\begin{tabular}{llllc}
\hline Neurone & Stimulation & & $\begin{array}{l}\text { Mean } \\
\text { latency }(\mu s)\end{array}$ & $S D(\mu s)$ \\
\hline 1 & Electrical & ipsilateral & 11074 & 281 \\
& & contralateral & 11114 & 373 \\
\hline 2 & \multirow{2}{*}{ Electrical } & ipsilateral & 14565 & 357 \\
& & contralateral & 14655 & 289 \\
\hline 3 & \multirow{2}{*}{ Tapping } & ipsilateral & 19504 & 722 \\
& & contralateral & 28043 & 1799 \\
\hline 4 & \multirow{2}{*}{ Tapping } & ipsilateral & 15183 & 331 \\
& & contralateral & 17566 & 1080 \\
\hline
\end{tabular}

oblique direction of the hammer from the medial to the lateral side so that the tap stretched the skin and soft tissues of the other side as well. There were no first component responses to contralateral stimulation when the taps were directed perpendicularly or obliquely from lateral to medial side. One neurone, however, responded in the first component even when the taps were delivered perpendicularly to the middle of the contralateral upper orbital margin (neurone 3 in Table 4). These responses had considerably longer latency and larger latency variation than responses to ipsilateral stimulation. Another neurone (neurone 4 in Table 4) responded in the first component when taps were applied to the contralateral infraorbital region.

In all four cases contralateral stimulation also produced responses in the second component which did not differ significantly from those obtained by ipsilateral stimulation.

DOUBLE RESPONSES AND BIMODAL DISTRIBUTION OF LATENCIES OF THE FIRST COMPONENT IN THE BLINK REFLEX

In eight neurones of five different subjects, single stimuli occasionally produced double responses in the first component of the blink reflex (Fig. 4). In two motoneurones double responses were obtained on electrical stimulation, in three on both electrical and mechanical stimulation, and in another three on mechanical stimulation only. In some of these neurones double responses appeared quite frequently or almost regularly, while in most they were only an occasional phenomenon. The time interval between the first and the second response was always greater than $3 \mathrm{~ms}$ and smaller than 


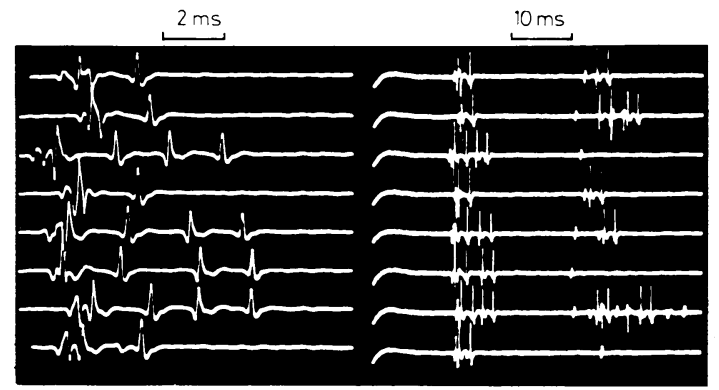

Fig. 4 An orbicularis oculi motoneurone (represented in the recording by two muscle fibres) showing double responses in both components of the blink reflex. Left traces are delayed $13.6 \mathrm{~ms}$ to display the responses in the first component at a higher sweep speed. The action potentials in the second response have slightly. lower amplitude due to subnormality of the muscle fibres at this short interdischarge interval. There is some interference of action potentials of other motor units.

$5 \mathrm{~ms}$. Two of the eight motoneurones also showed a bimodal distribution of latencies in the first component. The early and late responses appeared in irregular succession. but at least in one motoneurone the proportion of the early responses could be increased by increasing the stimulus strength. while the threshold strength produced almost exclusively late responses. The differences between the two latency peaks were 4.85 and 4.98 ms respecively for the two neurones (Fig. 5).

\section{Discussion}

The purpose of this study has been to determine whether the first component of the blink reflex is a monosynaptic or a polysynaptic response and our results can be summarised as follows.
1. Latency variation of responses of the first component of the blink reflex exceeded that of the direct responses of the same neurones 25.5 times on electrical stimulation and 61.8 times on mechanical stimulation.

2. Electrically evoked first component of the blink reflex showed 2.6 times larger latency variation than the $H$ reflex of the soleus muscle, while the mechanically evoked first component of the blink reflex had a latency variation 1.9 times larger than the tendon jerk of the single soleus motoneurones.

3. The estimates of the time needed for the central conduction of impulses between the trigeminal terminals and the facial motoneurone cells ranged between 2.40 and $6.60 \mathrm{~ms}$.

4. Responses typical for the first component of the blink reflex could be evoked occasionally by electrical and mechanical stimulation of the contralateral side of the face.

5 Several motoneurones fired twice to a single mechanical or electrical stimulus within the first component. the interval between the two responses being 3-5 ms. Some also showed a himodal distribution of latencies with an interval slightly less than $5 \mathrm{~ms}$.

LATENCY VARIATION

This phenomenon has been described before (Trontelj. 1973; Trontelj and Trontelj, 1973a, b). In the case of the $\mathrm{H}$ reflex it has been shown that more than $100 \mu \mathrm{s}$. that is more than two-thirds of the total variation. is caused by variation in the synaptic transmission time. On threshold stimulation the variation is increased, presumably because of the less steep rising slope of the compound EPSP. which increased the chances for greater latency variation ( $c f$. Coombs et al., 1957). However. even on threshold stimulation. the latency

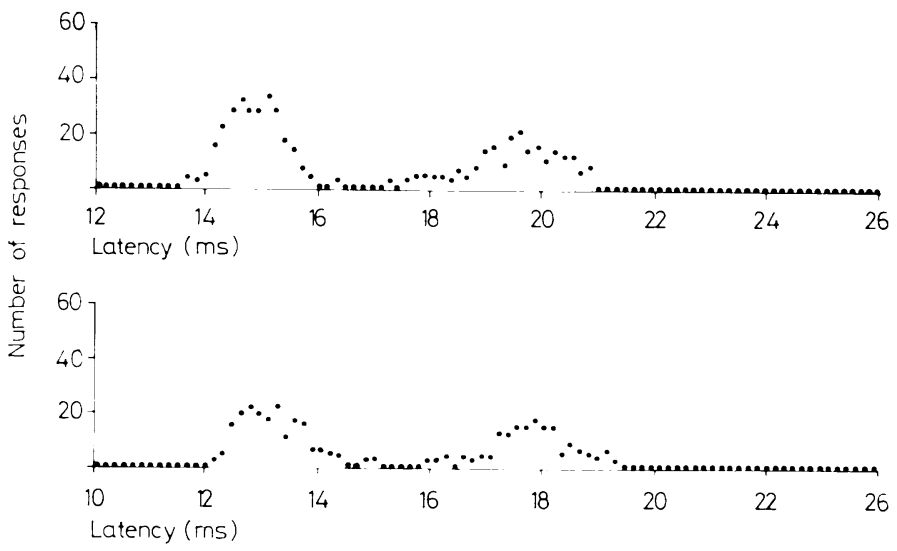

Fig. 5 Dual latency distribution of two motoncurones in the first component of the blink reflex in two subjects: 250 responses of each motoneurone. (Reproduced by permission of Brain Resear(h.) 
variation did not usually exceed $200 \mu \mathrm{s}$. In the case of the electrically evoked first component of the blink reflex, on the other hand, the latency variation was on average 2.6 times larger than in the $\mathrm{H}$ reflex. Figure 6 a shows very little overlapping between the two reflexes.

Mechanically evoked blink reflex showed even larger latency variation. This is presumably due, not to different reflex arcs, but to a less wellsynchronised afferent volley in the case of mechanical stimulation. An analogy can be drawn from comparison between the electrically evoked $\mathbf{H}$ reflex and mechanically evoked tendon jerk, the latter of which has a latency variation about three times larger. Figure $6 \mathrm{~b}$ compares the latency variation of the mechanically evoked first component of the blink reflex and that of the tendon jerk of soleus motoneurones. Again, there is some, although not much, overlapping of data.

It seems, therefore, that the reflex pathway of the first component of the blink reflex includes one or perhaps more additional synapses where additional latency variation is generated. On the other hand, the incomplete separation of the data for the two reflexes might suggest that either a part of the first component of the blink reflex is monosynaptic or part of the $\mathrm{H}$ reflex and tendon jerk is disynaptic. Bimodal distribution in the case of some $\mathrm{H}$ reflex responses (Trontelj, 1973) and some tendon jerks (Trontelj, in preparation) seems to suggest the latter possibility. On the other hand, the latency variation of the first component of the blink reflex is clearly much smaller than that of the second component, and the difference is even larger between the first component of the blink reflex and the early part of the flexion withdrawal reflex of tibialis anterior motoneurones.

\section{CENTRAL DELAY}

Neither of the two methods used to estimate the central transmission time in the brainstem is without certain difficulties. The main source of potential error was the estimation of conduction velocity along the trigeminal nerve fibres. We were unable to measure this velocity directly, and we used the same value as Kugelberg (1952), that is, $70 \mathrm{~m} / \mathrm{s}$. We assumed that the fastest conducting fibres should have a velocity at least as high as the facial nerve fibres, and probably higher, as is the general rule in mixed peripheral nerve. Our values for the facial nerve fibres ranged between 50.0 and 81.0 $\mathrm{m} / \mathrm{s}$ (Table 3 ). These values were measured for the peripheral part of the nerve distal to the stylomastoid foramen; the central values could conceivably be higher in both facial and trigeminal nerve, because of higher temperature and larger fibre diameters. Shahani (1970) measured the conduction velocity of the peripheral part of supraorbital nerve fibres distal to the foramen, and obtained values ranging from $32.5-44.0 \mathrm{~m} / \mathrm{s}$. These values apply to the peripheral portion of trigeminal fibres distal to the supraorbital foramen and,

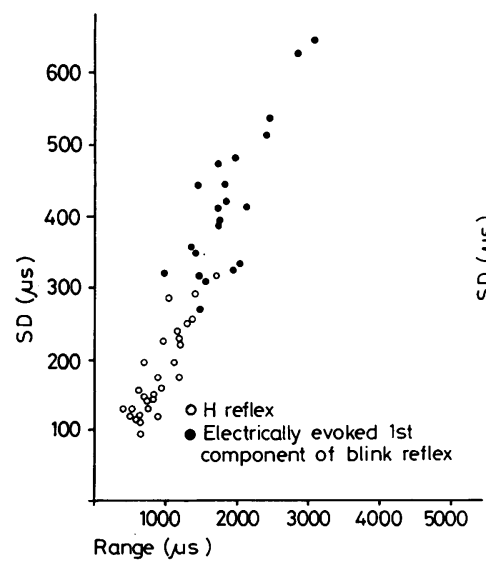

(a)

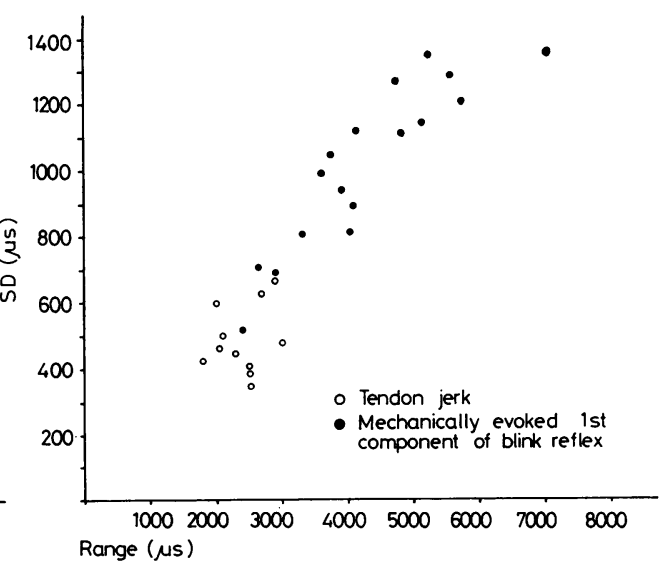

(b)

Fig. 6 (a) Latency variation (range plotted against SD) of electrically evoked blink reflex (21 motoneurones, $)$ compared to the $H$ reflex of the soleus muscle (25 motoneurones, $\bigcirc)$. Both reflexes were elicited at threshold stimulus strength. (b) Latency variation (range plotted against SD) of 11 facial motoneurones in the first component of the mechanically evoked blink reflex (O) compared to the latency variation of 11 soleus motoneurones in tendon jerk $(\bigcirc)$. Both reflexes were elicted with threshold stimulus strength. 
in our opinion, cannot be extrapolated to the central portion. Shahani's values are low because of tapering and branching of nerve fibres. Another possible source of error tending to decrease these values stems from the fact that Shahani's method of measurement was indirect, being calculated from the difference between reflex latencies obtained by stimulating at two points on the forehead. Shahani's proximal point of stimulation was over the supraorbital foramen where the number of afferent fibres depolarised by the supramaximal stimulus was necessarily much larger than that depolarised at a distal point high on the forehead. As follows from the present study, spatial summation of the afferent volley of this type shortens the latency on the average by more than $0.5 \mathrm{~ms}$, and in some cases up to $1.5 \mathrm{~ms}$. This could introduce a very significant error (up to $25-50 \%$ ) in determination of conduction velocity in this way. Thus Shahani's assumption that the first component of the human blink reflex is mediated by intermediately fast and not fastest conducting fibres may not be correct.

The method based on collision of antidromic and reflex impulses on the other hand, suffers from another disadvantage, (relative refractoriness of the motoneurone) which makes it difficult to determine accurately the interval between the two stimuli at which the collision occurs exactly in the initial segment of the axon. However, this difficulty could only make the obtained values too small but never larger than the true values. The two methods produced substantially matching results, and we may thus assume that they are at least close to true values.

Figure 3 also shows some correlation between the central and the reflex latency (minus terminal conduction time), longer central delays corresponding to longer latencies. This may lead to a conclusion that there are different central reflex pathways with differing numbers of interneurones.

\section{RESPONSES WITH CHARACTERISTICS OF THE FIRST} COMPONENT OF THE BLINK REFLEX TO STIMULATION OF THE CONTRALATERAL SIDE OF THE FACE

Contralateral responses frequently had very similar latency and latency variation as on ipsilateral stimulation. Sometimes one or the other value was considerably larger, but still significantly smaller than those of the second component of the blink reflex. This phenomenon can be taken to speak against the monosynaptic nature of the first component, as monosynaptic connections of the trigeminal fibres with the contralateral facial nerve do not seem very likely. Similar central delays and similar reflex latency variation suggest that both crossed and uncrossed reflex pathways include similar chains of interneurones. Contralateral mechanical stimulation with oblique position of the hammer from the medial to the lateral side regularly produced first component responses. This could be explained by stretching of the ipsilateral tissues. However, it seems to be of some importance that taps resulting in stretch were generally the most effective type of the stimulus, in agreement with the findings of Kugelberg (1952).

\section{DOUBLE RESPONSES AND BIMODAL LATENCY DISTRIBUTION IN THE FIRST COMPONENT OF THE BLINK REFLEX}

These two phenomena could be observed in more than $20 \%$ of the more closely studied motoneurones. They could be explained in several ways. First, the late responses could be caused by stimulation of some slower conducting afferent fibres. This is unlikely because the late responses had a lower threshold than the early ones, while the slower fibres should have a higher threshold for the electrical stimulus. Secondly, an interneurone in the reflex arc could respond with two impulses. This possibility is difficult to exclude but it would by itself speak against the monosynaptic nature of the response. Thirdly, the later of the two responses could be conducted through an alternative pathway including an additional interneurone. This possibility is supported by the somewhat larger latency variation of the late responses which applies both to the cases of double responses and those with bimodal latency distribution. The late responses cannot possibly be a part of the second component because their latency was much too short and the latency variation much too small. Fourthly, extra discharges with similar intervals occasionally occur in voluntary activity, most often following the first discharge after a pause (Stålberg and Trontelj, 1978). This may be due to inherent properties of the motoneurone rather than bimodal EPSP. However, the finding of both double responses and bimodal latency distribution in the same motoneurones in the blink reflex does support the possibility of bimodal EPSP.

Brown and Rushworth (1973) also measured latency variation in the first component of the blink reflex. They considered the maximum range of latency values but not the standard deviation. They compared their values to the previously published values for the $H$ reflex (Trontelj, 1968), concluded erroneously that there was no difference between the two reflexes, and took their data as proof that the first component of the blink reflex is monosynaptic.

Shahani (1970) also reported latency variation, 
but mostly on surface-detected response. In addition he made a few measurements on single motor units but, contrary to Brown and Rushworth, he interpreted his results as proof of the polysynaptic nature of this reflex. He suggested that there was no essential difference between the first component of the blink reflex and the first component of the flexion withdrawal reflex of the lower extremity. However, there is a clear difference between these two reflexes when studied on single motoneurones. The early responses in the flexion reflex show over 10 times larger latency variation as compared to the responses in the first component of the blink reflex (Trontelj et al., 1973).

Rushworth (1962) took the absence of habituation of the first component of the blink reflex as an argument against the polysynaptic nature of the reflex pathway. In our own studies (Trontelj et al., 1973, 1974) we have often seen no habituation in the bulbocavernous reflex when stimulation rate was lower than $3-5 \mathrm{~Hz}$. The latter reflex is definitely polysynaptic.

In conclusion, the results of this study indicate that the first component of the blink reflex is mediated predominantly, if not exclusively, by an oligosynaptic reflex arc which contains at least one and possibly more interneurones but is definitely shorter than that subserving the second component of the blink reflex.

\section{References}

Bechterew, W. (1901). Über Reflexe im Anlitz- und Kopf-gebiete. Neurologisches Centralblatt, 20, 930933.

Bender, L. F. (1968). Blink reflex test. Electroencephalography and Clinical Neurophysiology, 25, 409.

Brown, W. F., and Rushworth, G. (1973). Reflex latency fluctuations in human single motor unit. In New Developments in Electromyography and Clinical Neurophysiology. Vol. 3, pp. 660-665. Edited by J. E. Desmedt. Karger: Basel.

Coombs, J. S., Curtis, D. R., and Eccles, J. C. (1957). The generation of impulses in motoneurones. Journal of Physiology, 139, 232-242.

Ekstedt, J., Häggquist, P., and Stålberg, E. (1969). The construction of needle multi-electrodes for single fiber electromyography. Electroencephalography and Clinical Neurophysiology, 27, 540-543.

Ekstedt, J., and Stålberg, E. (1969). The effect of nonparalytic doses of d-tubocurarine on individual motor end-plates in man, studied with a new neurophysiological method. Electroencephalography and Clinical Neurophysiology, 27, 557-562.

Ekstedt, J., and Stålberg, E. (1973). Single fibre electromyography for the study of the microphysiology of the human muscle. In New Developments in Electromyography and Clinical Neurophysiology.
Vol. 1, pp. 89-112. Edited by J. E. Desmedt. Karger: Basel.

Ferrari, E., and Messina, C. (1968). Osservazioni elettrofisiologiche sui riflessi trigemino-facciali nell'uomo: "l'abitudine" della componente polisinaptica. Rivista di Neurologia, 38, 84-94.

Foerster, O. (1936). Handbuch der Neurologie. Edited by $O$. Bumke and $O$. Foerster. Springer: Berlin.

Gandiglio, G., and Fra, L. (1967). Further observations on facial reflexes. Journal of the Neurological Sciences, 5, 273-285.

Guillain, G. (1920). Le réflexe nasopalpébral (réflexe trijumeau-facial) et sa valeur pronostique dans la paralysie faciale. Comptes Rendus des Séances de la Société de Biologie (Paris), 83, 1394-1396.

Iwata, N., Kitai, S. T., and Olson, S. (1972). Afferent component of the facial nerve: its relation to the spinal trigeminal and facial nucleus. Brain Research, 43, 662-667.

Kugelberg, E. (1952). Facial reflexes. Brain, 75, 385396.

Lewandowsky, M. (1910). Die Störungen der Reflexe. In Handbuch der Neurologie. Erster Band-Algemeine Neurologie. Edited by M. Lewandowsky. Julius Springer: Berlin.

Lindquist, C., and Mårtensson, A. (1970). Mechanisms involved in the cat's blink reflex. Acta Physiologica Scandinavica, 80, 149-159.

Overend, W. (1896). Preliminary note on a new cranial reflex. Lancet, 1, 619. Cited in Shahani (1970).

Ramon Y. Cajal, S. (1909). Histologie du système nerveux. Cited in Struppler and Dobbelstein (1963). Maloine: Paris.

Rushworth, G. (1962). Observations on blink reflexes. Journal of Neurology, Neurosurgery, and Psychiatry, 25, 93-107.

Shahani, B. T. (1968). Effects of sleep on human reflexes with a double component. Journal of Neurology, Neurosurgery, and Psychiatry, 31, 574-579.

Shahani, B. T. (1969). A Study in Human Reflexes. Thesis, Oxford University. Cited in Shahani (1970).

Shahani, B. T. (1970). The human blink reflex. Journal of Neurology, Neurosurgery, and Psychiatry, 33, 792-800.

Shahani, B. T., and Young, R. R. (1968). A note on blink reflexes. Journal of Physiology (London), 198, 103-104.

Shahani, B. T., and Young, R. R. (1972). Human orbicularis oculi reflexes. Neurology (Minneapolis), 22, 149-154.

Shahani, B. T., and Young, R. R. (1973). Blink reflexes in orbicularis oculi. In New Developments in Electromyography and Clinical Neurophysiology. Vol. 3, pp. 641-648. Edited by J. E. Desmedt. Karger: Basel.

Simchowicz, T. (1922). Über den Nasenaugenreflex und den Nasenkinnreflex. Deutsche Zeitshrift für Nervenheilkunde, 75, 342-355.

Stålberg, E., and Ekstedt, J. (1973). Single fibre EMG and microphysiology of the motor unit in normal and diseased human muscle. In New Developments 
in Electromyography and Clinical Neurophysiology. Vol. 1, pp. 113-129. Edited by J. E. Desmedt. Karger: Basel.

Stålberg, E., and Trontelj, J. V. (1978). Single Fibre Electromyography. Unwin: Woking. In press.

Struppler, A., and Dobbelstein, H. (1963). Elektromyographische Untersuchung des Glabellareflexes bei verschiedenen neurologischen Störungen. Nervenarzt, 34, 347-352.

Trontelj, J. V. (1968). H-reflex of single motoneurones in man. Nature, 220, 1043-1044.

Trontelj, J. V. (1973). A study of the H reflex by single fibre EMG. Journal of Neurology, Neurosurgery, and Psychiatry, 36, 951-959.

Trontelj, M., and Trontelj, J. V. (1973a). First component of human blink reflex studied on single facial motoneurones. Brain Research, 53, 214-217.

Trontelj, J. V., and Trontelj, M. (1973b). F-responses of human facial muscles: a single motoneurone study. Journal of the Neurological Sciences, 20,
211-222.

Trontelj, J. K., Dimitrijević, M. R., and Prevec, T. S. (1968). A mechanic stimulator for eliciting tendon reflexes and somatosensory cerebral responses in man. Proceedings of the Symposium on Electronics in Medicine, 8/III-15. Ljubljana.

Trontelj, J. V., Janko, M., Godec, C., Rakovec, S., and Trontelj, M. (1974). Electrical stimulation for urinary incontinence. Urologia Internationalis, 29, 213-220.

Trontelj, J. V., Trontelj, M., and Stålberg, E. (1973). The jitter of single human muscle fibre responses in certain reflexes. 8th International Congress of Electromyography and Clinical Neurophysiology, Marseille. Abstract in Electroencephalography and Clinical Neurophysiology, 34, 818.

Wartenberg, R. (1945). The Examination of Reflexes: A Simplification. Year Book Publishers: Chicago.

Weingrow, S. M. (1933). Facial reflexes. Archives of Pediatrics, 50, 234-254. 